Check for updates

Cite this: RSC Adv., 2018, 8, 33688

\title{
Palladium nanoparticles loaded on nitrogen and boron dual-doped single-wall carbon nanohorns with high electrocatalytic activity in the oxygen reduction reaction $\uparrow$
}

\author{
Xueyou Tan, ${ }^{\mathrm{a}}$ Jinxuan Zhang, ${ }^{\mathrm{b}}$ Xiaohui Wu, ${ }^{\mathrm{a}}$ Yuanyuan Wang, ${ }^{\mathrm{a}}$ Meixian Li (D) ${ }^{\mathrm{b}}$ \\ and Zujin Shi $(\mathbb{D}$ *a
}

\begin{abstract}
Palladium nanoparticles with a diameter of 2-4 $\mathrm{nm}$ supported on nitrogen and boron dual-doped singlewall carbon nanohorns (Pd-NBCNHs) are synthesized via a one-step method and their electrocatalytic activities are investigated for the oxygen reduction reaction (ORR) in alkaline media. The electrochemical results demonstrate that the oxygen reduction peak potential of $\mathrm{Pd}-\mathrm{NBCNHs}$ is similar to that of commercial $20 \% \mathrm{Pt}-\mathrm{C}$. Furthermore, Pd-NBCNHs show a more positive half-wave potential than $20 \%$ $\mathrm{Pt}-\mathrm{C}$ and display better long-term stability and resistance to methanol than $20 \% \mathrm{Pt}-\mathrm{C}$, which is attributed to the synergetic effect of the Pd nanoparticles and NBCNHs. As NBCNHs have abundant pyrrolic nitrogen, charged sites and defective structures, they not only act as a carrier, but also provide the active sites for oxygen adsorption during the oxygen reduction reaction process. The outstanding electrochemical performance makes Pd-NBCNHs promising to be applied in fuel cells.
\end{abstract}

Received 30th August 2018

Accepted 24th September 2018

DOI: $10.1039 / \mathrm{c} 8 \mathrm{ra} 07248 \mathrm{e}$

rsc.li/rsc-advances is only $1 / 2-1 / 4$ of $\mathrm{Pt}$, which makes $\mathrm{Pd}$ an attractive alternative to Pt. ${ }^{10}$ In order to improve the ORR activity and reduce the amount of Pd, Pd-based alloyed (Pd-M, M $=\mathrm{Co},{ }^{11-13} \mathrm{Fe},{ }^{12} \mathrm{Ni},{ }^{12,13}$ $\mathrm{Sn},{ }^{14} \mathrm{Cu},{ }^{15,16}$ et al.) catalysts have been developed. However, some of these alloyed catalysts exhibited poor stability as a result of the dissolution or agglomeration of alloyed metal during the electrolysis process. This issue has been overcome with the development of carbon nanomaterials ${ }^{17}$ (graphene $(\mathrm{G})$, graphene oxide (GO), carbon nanotube (CNTs), et al.) due to their extraordinary electrical conductivity, stability and large specific area while being used as electric catalyst supports. ${ }^{18}$ For example, Pd or Pd-based alloy supported on carbon materials, such as G-PdAu@Pd, ${ }^{19}$ ER/PdCo-tGO ${ }^{20}$ and Pd-PEDOT/rGO, ${ }^{21}$ have been investigated to demonstrate improved ORR activity and sustainable stability. However, the smoothness of the surface of these carbon materials will make the interaction between the active site and the carrier too weak. In many cases, defects are actually responsible for many electrochemical activities ascribed to graphitic materials. ${ }^{22,23}$ The defects and irregular structures of graphene could be produced by doping heteroatoms, such as $\mathrm{N}$ and $\mathrm{B}$ atoms. However, the preparation of $\mathrm{N}$ and $\mathrm{B}$ dual-doped graphene require either a complicated two-step process or the use of metal catalysts, which is extraordinarily tedious and expensive for mass production. ${ }^{24-30}$ In addition, the existence of some unnecessary by-products and difficult-to-remove metal-impurities make it difficult to identify the nature of proposed synergistic effects. ${ }^{31}$
${ }^{a}$ Beijing National Laboratory for Molecular Science, State Key Lab of Rare Earth Materials Chemistry and Applications, College of Chemistry and Molecular Engineering, Peking University, Beijing 100871, P. R. China.E-mail: zjshi@pku.edu.cn ${ }^{b}$ Beijing National Laboratory for Molecular Sciences, College of Chemistry and Molecular Engineering, Peking University, Beijing 100871, P. R. China

$\dagger$ Electronic supplementary information (ESI) available: More characterizations of samples. See DOI: 10.1039/c8ra07248e 
Single-walled carbon nanohorn $(\mathrm{CNH})$, is a new type of carbon nanomaterial that can be mass produced by the arc method without the metal catalysts. ${ }^{32}$ The most distinctive feature of $\mathrm{CNH}$ is its "dahlia flower"-like morphology formed via aggregation of the angled structure, resulting in more defects and nanoscale pores that disperse the metal nanoparticles (NPs) and prevent the aggregation of metal NPs. ${ }^{3,34}$ Compared to graphene, the inherent defect structure of CNHs may be more favorable for adsorbing oxygen and promote the oxygen reduction reaction. Moreover, CNHs can increase the amount of defects by in situ doping of heteroatoms without the using of the metal catalyst. ${ }^{35}$ Furthermore, the dual-doping could disrupt the electroneutrality of graphitic $\pi$-system in carbon materials and enhance the catalytic activity to a far extent due to the synergistic effect between the doped atoms. ${ }^{24}$ The experimental results and density functional theory (DFT) calculations show that the dopants have a lower (as B) or a higher (as N) electronegativity than that of carbon, could create charge $\left(\mathrm{B}^{+}\right.$or $\left.\mathrm{C}^{+}\right)$ sites favorable for $\mathrm{O}_{2}$ adsorption to facilitate the ORR process. $^{36,37}$ Therefore, $\mathrm{N}$ and $\mathrm{B}$ dual-doped single-wall carbon nanohorns (NBCNHs), as an emerging carbon nanomaterial, are an alternative option thanks to large-scale production via one-step doping in situ by DC arc-discharge method without using costly metal catalysts.

CNHs also exhibit good catalytic activity toward ORR because of its high electrical conductivity, good stability and methanol tolerance. ${ }^{38}$ Our group has found that nitrogen and boron dualdoped CNHs (NBCNHs) would largely improve their catalytic activity for ORR. However, ORR activity of NBCNHs are still lower than that of commercial Pt-C with $20 \mathrm{wt} \% \mathrm{Pt}$ loading $(20 \%$ Pt-C). Further improvement can be achieved by the assembly of two active components (Pd NPs and NBCNHs) owing to unique properties of CNHs, as well as synergistic effect. To our best knowledge, Pd NPs loaded on the different dual-atom doped CNHs remain unexplored and their catalytic properties in ORR have not been reported yet.

In this work, Pd NPs loaded on N and B atoms dual-doped single-wall carbon nanohorns (Pd-NBCNHs) were synthesized by one-step reduction method and their ORR activities were studied in alkaline media. The electrochemical measurements indicate that Pd-NBCNHs exhibits superior electrocatalytic activity with an onset potential of $-0.01 \mathrm{~V} v s$. saturated calomel electrode (SCE), similar to that of the commercial $20 \% \mathrm{Pt}-\mathrm{C}$, and half-wave potential of the former is more positive than $20 \%$ Pt-C. Furthermore, Pd-NBCNHs shows better long-term durability and methanol tolerance for ORR in the alkaline media than those of commercial $20 \% \mathrm{Pt}-\mathrm{C}$, which makes it promising as cathode catalyst in fuel cells.

\section{Experiment}

\section{Synthesis of NBCNHs}

Pure CNHs were prepared by DC arc-discharge method according to our previous report. ${ }^{39}$ Boron and nitrogen dualdoped CNHs (NBCNHs) were produced by DC arc-vaporization of carbon rod that contains $\mathrm{B}_{4} \mathrm{C}$ and melamine composites in 400 Torr pressure of $\mathrm{CO}^{38}$ To remove amorphous carbon, the rough NBCNHs were roasted at $430{ }^{\circ} \mathrm{C}$ for $2 \mathrm{~h}$ in the air, Then the obtained NBCNHs were purified by a gravitational sedimentation method to remove giant graphite-balls.

\section{Preparation of catalysts}

Pd-NBCNHs was prepared by one-step reduction method according to the previous report. ${ }^{40}$ Briefly, $40 \mathrm{mg}$ NBCNHs were dispersed in $8 \mathrm{~mL}$ anhydrous ethanol by sonication at room temperature for 30 minutes. Then, $2 \mathrm{~mL}$ of $\mathrm{K}_{2} \mathrm{PdCl}_{4}$ aqueous solution was added into the suspension gradually under ultrasonic conditions, holding for another 2 hours. Subsequently, $20 \mathrm{mg} \mathrm{NaBH} 4$ in $1 \mathrm{~mL}$ deionized water was added for another 40 minutes. Finally, the mixture was filtered and washed with deionized water, dried in a vacuum oven at $80{ }^{\circ} \mathrm{C}$ for $12 \mathrm{~h}$.

\section{Characterization}

The morphology of Pd-NBCNHs was observed by transmission electron microscopy (TEM) at an accelerating voltage of $200 \mathrm{kV}$ (JEOL-2100). The Pd content in the sample was examined by inductively coupled plasma-atomic emission spectrometer (ICP, Prodigy 7). The X-ray diffraction (XRD) patterns were performed on a Rigaku MiniFlex 600 using filtered $\mathrm{Cu} \mathrm{K} \alpha$ radiation. Raman measurements were investigated using a $530 \mathrm{~nm}$ laser in the back-scattering configuration on a Jobin-Yvon HR800 Spectrometer to obtain the contents of defect in Pd-NBCNHs. Thermogravimetric analysis (TGA) was recorded on a Q600 thermogravimetric analyzer (Thermal Analysis Inc., USA) from room temperature to $1000{ }^{\circ} \mathrm{C}$ at a rate of $10{ }^{\circ} \mathrm{C} \mathrm{min}{ }^{-1}$ under an air flow of $100 \mathrm{~mL} \mathrm{~min}{ }^{-1}$. The chemical states of elements and the content in material were tested by X-ray photoelectron spectroscopy (XPS, Axis Ultra). The specific surface area and pore-size distribution were determined using the BrunauerEmmett-Teller (BET) method by measuring the adsorption of $\mathrm{N}_{2}$ on an ASAP2010 volumetric adsorption analyzer.

\section{Electrochemical measurements}

All electrochemical tests were carried out with a CHI660C electrochemical workstation ( $\mathrm{CH}$ Instrument, Chenhua Company, Shanghai, China). A standard three-electrode cell was employed with a glassy carbon electrode (GCE, $3 \mathrm{~mm}$ in diameter) or rotating disk electrode (RDE, $3 \mathrm{~mm}$ in diameter) modified with the sample as a working electrode, a saturated calomel electrode (SCE) as the reference electrode and a Pt plate as the counter electrode. For typical fabrication of Pd-NBCNHs modified electrode, $2.0 \mathrm{mg}$ catalyst in $1.0 \mathrm{~mL}$ of anhydrous ethanol was dispersed by ultrasonication for 30 minto prepare the catalyst ink. $35 \mu \mathrm{L}$ of the ink was dropped onto the surface of the GCE and dried ambient temperature, followed by covering a layer of $3 \mu \mathrm{L}$ of Nafion ionomers (0.5 wt\%). Cyclic voltammograms (CVs) of samples were performed in $\mathrm{N}_{2^{-}}$and $\mathrm{O}_{2^{-}}$ saturated $0.1 \mathrm{M} \mathrm{KOH}$ solution. Linear sweep voltammetry (LSV) measurements were conducted at a scan rate of $10 \mathrm{mV} \mathrm{s}^{-1}$ with a glassy carbon rotating disk electrode (3 mm diameter). For comparison, Pd-CNHs, ${ }^{40} \mathrm{Pd}-\mathrm{BCNHs}^{40}$ and $\mathrm{Pd}-\mathrm{NCNHs}^{40}$ synthesized in the previous article and the commercial catalyst $(20 \%$ Pt-C) were also loaded onto the GC electrode with the same 
procedure. The RDE data in alkaline solution was analyzed using the Koutecky-Levich (K-L) eqn $(1),{ }^{19}$ where $j, j_{\mathrm{k}}, j_{\mathrm{d}}$ are the measured, the kinetic and diffusion-limited current densities, respectively. $n$ is the number of exchanged electrons per $\mathrm{O}_{2}$ molecule, $F$ is the Faraday constant (96 $486 \mathrm{C} \mathrm{mol}^{-1}$ ), $k$ is the rate constant for $\mathrm{O}_{2}$ reduction, $D_{\mathrm{O}}$ is the diffusion coefficient of oxygen $\left(1.9 \times 10^{-5} \mathrm{~cm}^{2} \mathrm{~s}^{-1}\right), \nu$ is the kinematic viscosity of the electrolyte $\left(0.01 \mathrm{~cm}^{2} \mathrm{~s}^{-1}\right), C_{\mathrm{O}}$ is the concentration of oxygen in the bulk $\left(1.2 \times 10^{-6} \mathrm{~mol} \mathrm{~cm}{ }^{-3}\right)$, and $\omega$ is the rotation rate of electrode.

$$
\frac{1}{j}=\frac{1}{j_{\mathrm{k}}}+\frac{1}{j_{\mathrm{d}}}=\frac{1}{n F k C_{\mathrm{O}}}+\frac{1}{0.2 n F D_{\mathrm{O}}^{2 / 3} \nu^{-1 / 6} C_{\mathrm{O}} \omega^{1 / 2}}
$$

\section{Results and discussion}

As shown in Fig. 1, uniform Pd NPs with a size of 2-4 nm are homogeneously dispersed on NBCNHs with "dahlia flower"-like morphology formed via aggregation of the angled structure. ICP measurements confirm that Pd content (wt\%) in Pd-NBCNHs is $4.70 \mathrm{wt} \%$. These results indicate that the Pd NPs have been loaded on NBCNHs successfully. Furthermore, the crystalline pattern of Pd-NBCNHs was identified by XRD analysis. As shown in Fig. 2A, the diffraction peak of Pd-NBCNHs at $40.11^{\circ}$ corresponds to the (111) plane of the face-centered cubic (FCC) structure of Pd. ${ }^{41}$ The lattice $d$-spacing of (111) plane of $\mathrm{Pd}$ calculated is approximately $0.225 \mathrm{~nm}$ according to the Bragg's law, ${ }^{42}$ which is confirmed by HRTEM in Fig. 1B. The broad peak at $26.01^{\circ}$ is assigned to the (002) facet of $\mathrm{CNHs},{ }^{43}$ indicating that the CNHs are somewhat disordered rather than being ideally graphitic. This lattice distortion within the c-planes is reflected by a larger $d$-spacing of the (002) basal planes in the carbon

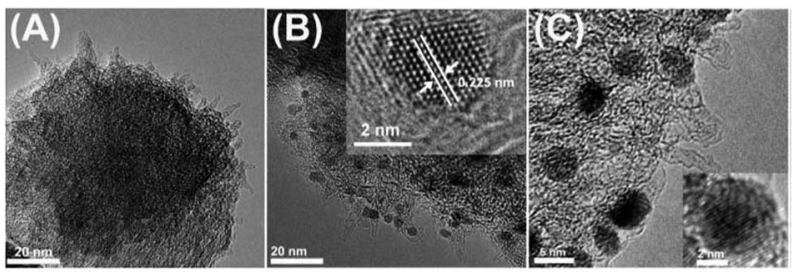

Fig. 1 TEM images of (A) NBCNHs (B) Pd-NBCNHs and (C) PdNBCNHs after $1-t$ chronoamperometry measurements in $\mathrm{O}_{2}$-saturated $0.1 \mathrm{M} \mathrm{KOH}$ solutions for $9000 \mathrm{~s}$. Insets show Pd NPs at a high magnification
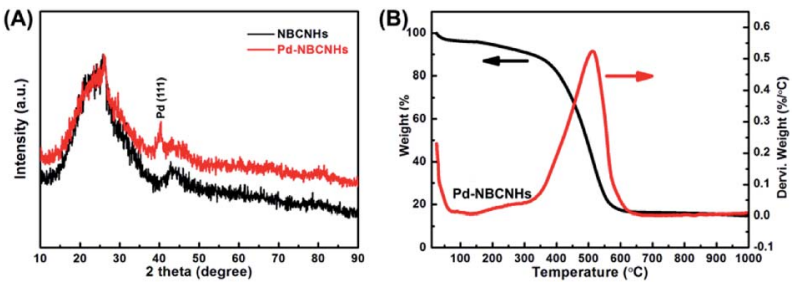

Fig. 2 (A) XRD diffraction patterns of NBCNHs and Pd-NBCNHs; (B) TGA and DTG curves of Pd-NBCNHs.

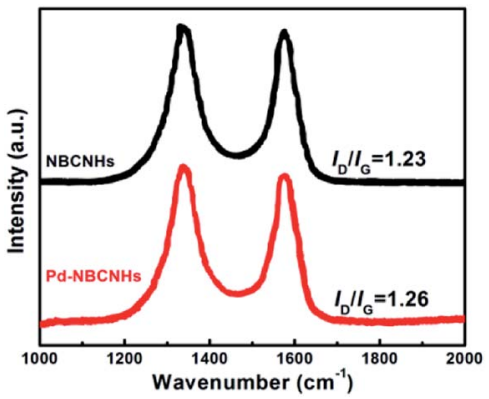

Fig. 3 Raman spectra of $\mathrm{Pd}-\mathrm{NBCNHs}$, the $I_{\mathrm{D}} / I_{\mathrm{G}}$ represent the intensity ratio of $D$ band and $G$ band of catalysts, respectively.

relative to that in a well-ordered structure of graphite. ${ }^{44}$ DTG curves of Pd-NBCNHs show the only characteristic peak of NBCNHs (Fig. 2B), indicating that the sample contains no other carbon impurities such as amorphous carbon or graphitic carbon.

Moreover, the surface defects of the Pd-NBCNHs were investigated by Raman spectroscopy. As shown in Fig. 3, the D band at approximately $1352 \mathrm{~cm}^{-1}$ and the $\mathrm{G}$ band at $1589 \mathrm{~cm}^{-1}$ represent the disordered carbon and the graphitic carbon peak, respectively. ${ }^{45}$ The higher $I_{\mathrm{D}} / I_{\mathrm{G}}$ ratio of doping carbon material implies the much more disordered carbon and defect in the sample. ${ }^{46}$ The high $I_{\mathrm{D}} / I_{\mathrm{G}}$ of Pd-NBCNHs $\left(I_{\mathrm{D}} / I_{\mathrm{G}}=1.26\right)$ indicates that it have more defective carbon compared with Pd-CNHs $\left(I_{\mathrm{D}} /\right.$ $\left.I_{\mathrm{G}}=1.06\right),{ }^{40}$ suggesting that the defective carbon of CNHs increases with the introduction of heteroatom. Notably, the $I_{\mathrm{D}} /$ $I_{\mathrm{G}}$ of NBCNHs $\left(I_{\mathrm{D}} / I_{\mathrm{G}}=1.23\right)$ does not change significantly after loading Pd NPs. The results of Raman show that disordered carbon and defect of NBCNHs have not changed significantly after loading Pd NPs. The more defective carbon in electrocatalyst could facilitate the adsorption of oxygen molecules and breakage of O-O bond, improving the ORR activity.

The existence and content of doped heteroatoms in PdNBCNHs were investigated by XPS spectra. As shown in Fig. $4 \mathrm{~A}$, the peaks at $335.7\left(\mathrm{Pd} 3 \mathrm{~d}_{5 / 2}\right)$ and $341.2\left(\mathrm{Pd} 3 \mathrm{~d}_{3 / 2}\right), 337.2$ $\left(\mathrm{Pd} 3 \mathrm{~d}_{5 / 2}\right)$ and $342.3 \mathrm{eV}\left(\mathrm{Pd} 3 \mathrm{~d}_{5 / 2}\right)$ are assigned to $\mathrm{Pd}^{0}$ and $\mathrm{Pd}^{2+}$, respectively. ${ }^{47}$ In Fig. $4 \mathrm{~B}$, The B 1 s peaks can be fitted into four components. The peaks at $186.4 \mathrm{eV}, 187.7 \mathrm{eV}, 189.7 \mathrm{eV}$ and $192.5 \mathrm{eV}$ are ascribed to $\mathrm{B}-\mathrm{C}_{4}, \mathrm{~B}-\mathrm{C}_{3}, \mathrm{~B}-\mathrm{CO}_{2}$ (B atoms are surrounded by carbon and oxygen atoms) and $\mathrm{B}-\mathrm{O}$ structure, respectively. ${ }^{48}$ The presence of $\mathrm{B}-\mathrm{C}_{3}$ structure indicates that the $B$ atoms have been doped into the graphitic lattice in NBCNHs. The XPS spectra of $\mathrm{N}$ 1s of Pd-NBCNHs can be divided into four peaks, including $\mathrm{N} 1$ (398.6 eV, pyridinic $\mathrm{N}), \mathrm{N} 2(400.1 \mathrm{eV}$, pyrrolic N), N3 (401.3 eV, quaternary $\mathrm{N}$ ) and $\mathrm{N} 4(402.4 \mathrm{eV}$, pyridine- $N$-oxide) structure. $^{\mathbf{4 8 4 9}}$ Pd-NBCNHs shows a high proportion of pyrrolic $\mathrm{N}(73.34 \%)$ that has been confirmed to play an important role in the ORR process. These results confirm that the $\mathrm{N}$ and $\mathrm{B}$ atoms have been incorporated into the corresponding carbon materials.

The ORR activity of Pd-NBCNHs was explored by cyclic voltammetry (CV) measurement. As shown in Fig. 5A, Pd-NBCNHs shows a pronounced cathodic peak at $-0.190 \mathrm{~V}$ in $\mathrm{O}_{2}$-saturated 

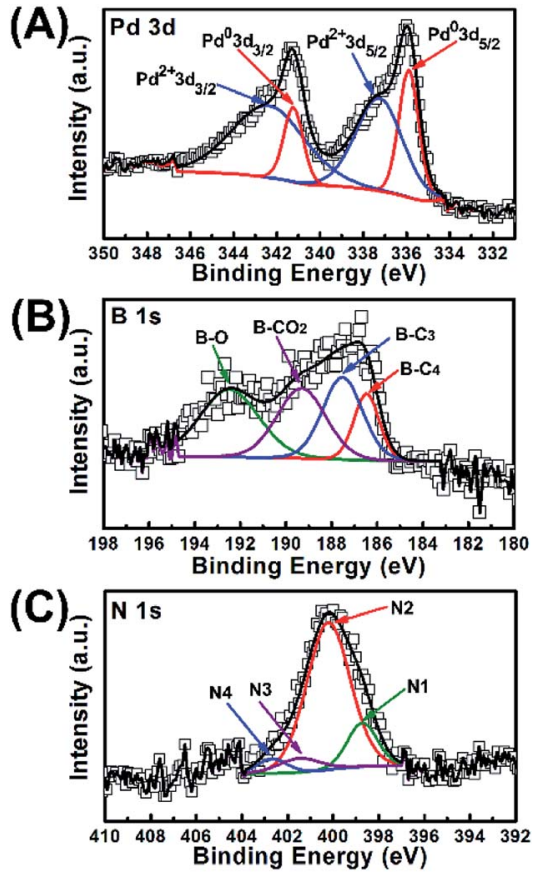

Fig. 4 (A) Pd 3d XPS spectra of Pd-NBCNHs; (B) B 1s XPS spectra of $\mathrm{Pd}-\mathrm{NBCNHs}$; (C) N 1s XPS spectra of Pd-NBCNHs.
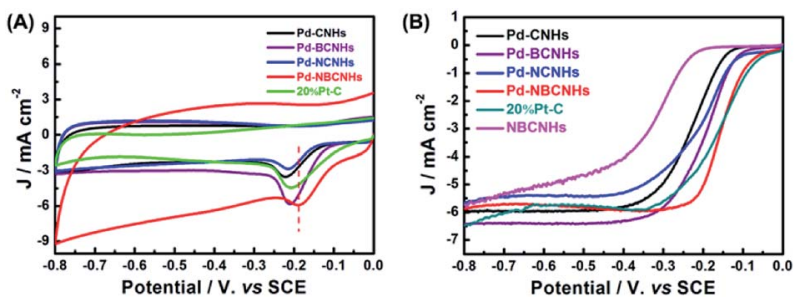

Fig. 5 (A) CV curves of samples and $20 \% \mathrm{Pt}-\mathrm{C}$ at $50 \mathrm{mV} \mathrm{s}^{-1}$ in $\mathrm{O}_{2}$ saturated $0.1 \mathrm{M} \mathrm{KOH}$ solution; (B) LSV curves of the samples in $\mathrm{O}_{2-}$ saturated $0.1 \mathrm{M} \mathrm{KOH}$ solution at a rotating rate of $1600 \mathrm{rpm}$ with a sweep rate of $10 \mathrm{mV} \mathrm{s}^{-1}$.

$0.1 \mathrm{M} \mathrm{KOH}$ solution, confirming a substantial ORR process (Fig. 4A). For comparison, Pd-CNHs, ${ }^{40}$ Pd-BCNHs ${ }^{40}$ and Pd$\mathrm{NCNHs}^{40}$ synthesized in the previous article were also tested using cyclic voltammetry. The ORR peak potential of Pd-CNHs, Pd-BCNHs and Pd-NCNHs are respectively at $-0.221 \mathrm{~V}$, $-0.210 \mathrm{~V}$ and $-0.215 \mathrm{~V}$ in Fig. 5A. Pd-NBCNHs shows a more positive peak potential than Pd-CNHs, Pd-BCNHs and PdNCNHs, indicating a better catalytic activity. It is worth mentioning that the oxygen reduction peak potential of PdNBCNHs is similar to that of commercial $20 \% \mathrm{Pt}-\mathrm{C}(-0.207 \mathrm{~V}$, vs. SCE) in Fig. 5A. The CV result indicates that Pd-NBCNHs exhibits comparable ORR activity to that of $20 \% \mathrm{Pt}-\mathrm{C}$ in terms of peak potential.

Subsequently, linear sweep voltammograms (LSVs) were further performed to investigate the catalytic properties of PdNBCNHs and $20 \% \mathrm{Pt}-\mathrm{C}$. The onset and half-wave potential are the main parameters to measure the catalytic performance of the material. The more positive onset and half-wave potential demonstrate the smaller overpotential and higher catalytic
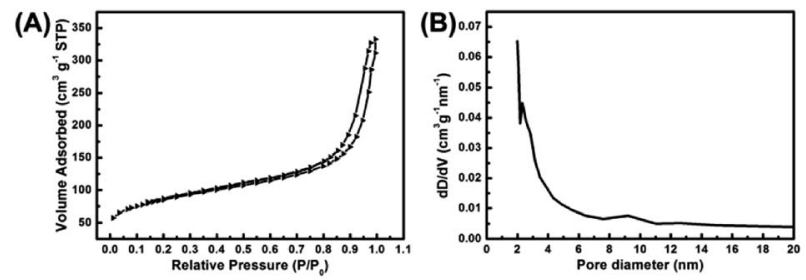

Fig. 6 (A) $\mathrm{N}_{2}$ adsorption-desorption isotherms and (B) corresponding Barrett-Joyner-Halenda (BJH) pore-size distribution curve determined from the desorption branch of the isotherm of Pd-NBCNHs.

activity of catalyst toward ORR. As shown in Fig. 5B, PdNBCNHs exhibits an onset potential $(-0.01 \mathrm{~V})$ that is close to that of $20 \%$ Pt-C, while onset potential of Pd-CNHs, Pd-BCNHs and Pd-NCNHs shift negatively to $-0.15 \mathrm{~V},-0.08 \mathrm{~V}$ and $-0.10 \mathrm{~V}$, respectively. Besides, the half-wave potential $\mathrm{E}_{1 / 2}$ of Pd-CNHs, Pd-BCNHs, Pd-NCNHs, Pd-NBCNHs and $20 \%$ Pt-C are determined to be $-0.229 \mathrm{~V},-0.195 \mathrm{~V},-0.203 \mathrm{~V},-0.152 \mathrm{~V}$ and $-0.167 \mathrm{~V}$, respectively. The positive shift of onset and half-wave potential indicate that Pd-NBCNHs displays comparable catalytic activity to that of $20 \% \mathrm{Pt}-\mathrm{C}$ and is able to significantly reduce the overpotential for ORR than Pd-CNHs, Pd-BCNHs and Pd-NCNHs. Though the BET surface area of Pd-NBCNHs (296.9 $\left.\mathrm{m}^{2} \mathrm{~g}^{-1}\right)$ in Fig. 6A is smaller than that of Pd-CNHs $\left(672.5 \mathrm{~m}^{2}\right.$ $\left.\mathrm{g}^{-1}\right),{ }^{40}$ Pd-BCNHs $\left(341.7 \mathrm{~m}^{2} \mathrm{~g}^{-1}\right)^{40}$ and Pd-NCNHs $\left(505.9 \mathrm{~m}^{2}\right.$ $\left.\mathrm{g}^{-1}\right),{ }^{40}$ its electrocatalytic performance is still superior to that of Pd-CNHs, Pd-BCNHs and Pd-NCNHs, indicating that a larger surface area does not always produce better catalytic activity and current density. The similar argument also has been reported in the study for Pd@CN catalysing ethanol electrooxidation.$^{41}$ In this work, we infer that the larger average pore size of Pd-NBCNHs $(5.16 \mathrm{~nm})$ in Fig. 6B could yield easier mass transportation and consequently show better performance for ORR than that of Pd-BCNHs $(4.30 \mathrm{~nm}),{ }^{40}$ Pd-NCNHs $(4.05 \mathrm{~nm})^{40}$ and Pd-CNHs $(3.73 \mathrm{~nm}) .^{40}$ Pd NPs combined with carbon nanomaterials have been reported in the previous articles. ${ }^{19-21} \mathrm{It}$ is notable that the material in this work exhibits higher ORR activity about onset potential than the composites reported before (Table 1), suggesting that Pd-NBCNHs is a good choice in fuel cells operated in alkaline media.

LSV curves of the samples at various rotation speeds from 500 to $2500 \mathrm{rpm}$ were measured to obtain more information about ORR kinetics and calculate the electron transfer numbers per $\mathrm{O}_{2}$ during the ORR process (Fig. 7A-D). Koutecky-Levich (KL) equation of all samples showed good linearity between $j^{-1}$ and $\omega^{-1 / 2}$ in Fig. 7E. On the basis of K-L equation ${ }^{19}$ and the slopes of these $\mathrm{K}-\mathrm{L}$ plots at $-0.4 \mathrm{~V}$, the electron transferred numbers per $\mathrm{O}_{2}$ of Pd-CNHs, Pd-BCNHs, Pd-NCNHs and PdNBCNHs are determined to be close to 4 . The result suggests the efficient reduction of $\mathrm{O}_{2}$ to $\mathrm{H}_{2} \mathrm{O}$ for Pd-XCNHs $(\mathrm{X}=\mathrm{N}$, B or $\mathrm{NB})$ via the desired four-electron pathway. ${ }^{4,50}$

To evaluate the stability of Pd-NBCNHs, I- $t$ chronoamperometry measurement was performed. As shown in Fig. 8A, Pd-NBCNHs still retains $95.3 \%$ of its initial current after $9000 \mathrm{~s}$, demonstrating a much better stability of Pd-NBCNHs than that of $20 \% \mathrm{Pt}-\mathrm{C}$, which lose more than $48 \%$. The good 
Table 1 Comparison on catalytic activity of Pd-NBCNHs and other materials

\begin{tabular}{lcccc}
\hline Sample & Pd-NBCNHs & G-AuPd@Pd ${ }^{19}$ & Pd/PEDOT/rGO $^{21}$ & ER/Pd-Co-tGO $^{20}$ \\
\hline Pd content $(w t \%)$ & 4.70 & 78.0 & 17.3 & 7.75 \\
Onset potential $(V$, vs. SCE) & -0.010 & 0.046 & -0.0293 & -0.146
\end{tabular}
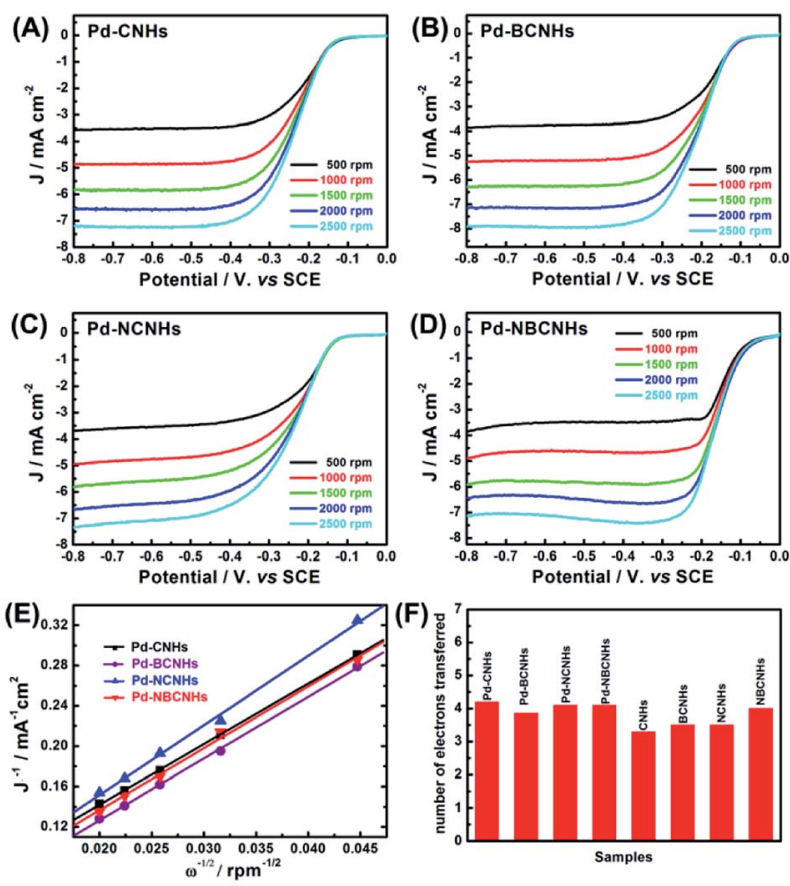

Fig. 7 RDE voltammograms of (A) Pd-CNHs, (B) Pd-BCNHs, (C) Pd$\mathrm{NCNHs}$ and (D) Pd-NBCNHs in $\mathrm{O}_{2}$-saturated $0.1 \mathrm{M} \mathrm{KOH}$ solution at $10 \mathrm{mV} \mathrm{s}^{-1}$ with the various rotating speeds; (E) Koutecky-Levich plots of $j^{-1}$ versus $\omega^{-1 / 2}$ of $\mathrm{Pd}-\mathrm{CNH}$, Pd-BCNHs, Pd-NCNHs and Pd$\mathrm{NBCNHs}$ at $-0.4 \mathrm{~V}$; (F) the number of electrons transferred per $\mathrm{O}_{2}$ of samples at $0.4 \mathrm{~V}$.

long-term stability of Pd-NBCNHs can be attributed to the large specific area and nanospaces of NBCNHs, which can inhibit Pd nanoparticles from agglomeration (Fig. 1C) and furthermore prevents the loss of available active site during the longtimescale ORR process. Methanol tolerance of ORR electrocatalyst is one of the important factors for potential application in the direct methanol fuel cells, because methanol may cross over the membrane and damage the ORR activity of the catalyst.
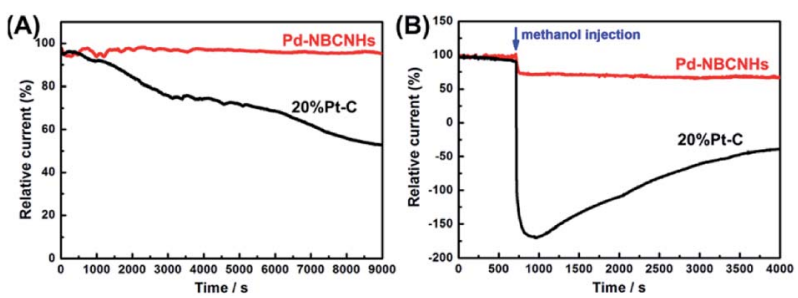

Fig. 8 (A) $1-t$ chronoamperometry measurements of $\mathrm{Pd}-\mathrm{NBCNH}$ and $20 \% \mathrm{Pt}-\mathrm{C}$ at $-0.3 \mathrm{~V}$ in $\mathrm{O}_{2}$-saturated $0.1 \mathrm{M} \mathrm{KOH}$ solutions at a rotating rate of $1000 \mathrm{rpm}$ for $9000 \mathrm{~s}$; (B) methanol crossover tests of Pd$\mathrm{NBCNH}$ and $20 \% \mathrm{Pt}-\mathrm{C}$ at $-0.3 \mathrm{~V}$ in $\mathrm{O}_{2}$-saturated $0.1 \mathrm{M} \mathrm{KOH}$ solutions at a rotation rate of $1000 \mathrm{rpm}$ with addition of $3 \mathrm{M}$ methanol at $700 \mathrm{~s}$.
With the injection of methanol (Fig. 8B), the current density of Pd-NBCNHs suffers only a small drop and then remains substantially stable, while a rapid current falloff is observed in $20 \%$ Pt-C. This result implies that Pd-NBCNHs has a much stronger tolerance to methanol crossover.

To explain the role of NBCNHs in ORR, the ORR activity of metal-free CNHs, including BCNHs, NCNHs and NBCNHs, was tested. As shown in Fig. S1, $\dagger$ metal-free CNHs exhibit a welldefined oxygen reduction peak in $\mathrm{O}_{2}$-saturated $0.1 \mathrm{M} \mathrm{KOH}$ solution. In Fig. S1, $\uparrow$ NBCNHs show a more positive peak potential $(-0.245 \mathrm{~V})$ compared with other metal-free $\mathrm{CNHs}$ (BCNHs, $-0.323 \mathrm{~V}$; NCNHs, $-0.332 \mathrm{~V}$; and CNHs, $-0.358 \mathrm{~V}$ ), indicating the increasing ORR activity in the presence of NBCNHs. In addition, the number of exchanged electrons per oxygen molecule at $-0.4 \mathrm{~V}$ for CNHs, NCNHs, BCNHs and NBCNHs are 3.3, 3.5, 3.5 and 4.0 according to LSV curves (Fig. 9) and K-L equation, respectively. These results imply that NBCNHs are more beneficial to ORR than other single-doped CNHs or pure CNHs. It was reported that the high content of $\mathrm{N}$ and $\mathrm{B}$ atoms in the catalysts can provide oxygen adsorption sites and weaken the $\mathrm{O}-\mathrm{O}$ bonds. ${ }^{4,51}$ This is because they can induce charge redistribution to create charged sites $\left(\mathrm{C}^{+}\right.$or $\left.\mathrm{B}^{+}\right)$ for $\mathrm{O}_{2}$ adsorption due to the different electronegativity with carbon. ${ }^{36,37}$ Compared with NCNHs (N atoms: 1.33 at $\left.\%\right)^{40}$ and BCNHs (B atoms: 0.71 at\%), ${ }^{40}$ NBCNHs (the total number of $\mathrm{N}$ and B atoms: 2.88 at\%) in this work contain more doped heteroatoms, and would derive much more charged site $\left(\mathrm{C}^{+}\right.$and $\mathrm{B}^{+}$) for $\mathrm{O}_{2}$ adsorption, thereby increasing the ORR catalytic activity.

Obviously, oxygen reduction peak potential of Pd-XCNHs is more positive than that of the corresponding metal-free CNHs,
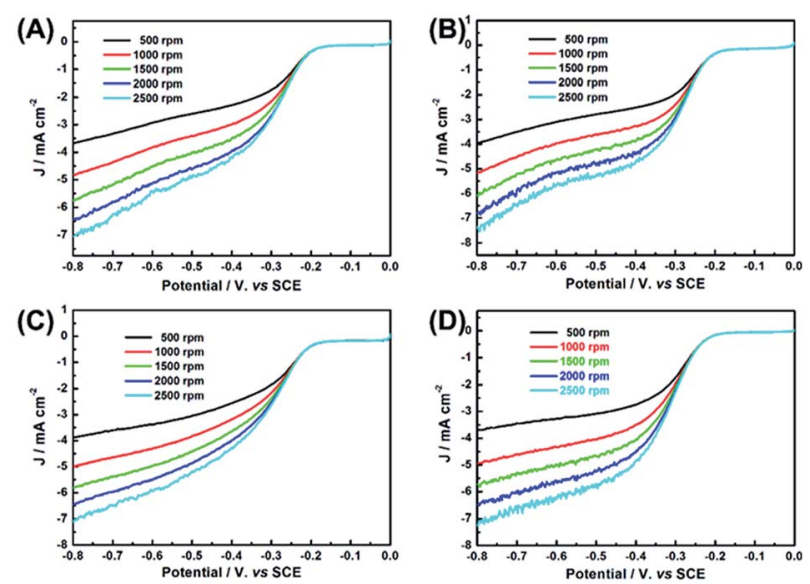

Fig. 9 RDE voltammograms of (A) $\mathrm{CNHs}$, (B) BCNHs, (C) NCNHs and (D) $\mathrm{NBCNHs}$ in $\mathrm{O}_{2}$-saturated $0.1 \mathrm{M} \mathrm{KOH}$ solution at $10 \mathrm{mV} \mathrm{s}^{-1}$ with the various rotating speeds. 
suggesting the increased electroactivity after loading Pd NPs. The promotional effect of Pd NPs toward ORR is well known. PdCNHs (4.69 wt\% of Pd), ${ }^{40}$ Pd-BCNHs (4.60 wt\% of Pd), ${ }^{40} \mathrm{Pd}-$ NCNHs $\left(4.75 \mathrm{wt} \%\right.$ of Pd) ${ }^{40}$ and Pd-NBCNHs (4.70 wt\%) have a nearly equivalent proportion of Pd. However, Pd-NBCNHs displays the highest activity while Pd-CNHs shows the poorest performance among Pd-XCNHs. The superior ORR activity of Pd-NBCNHs can be ascribed to the following factors: (i) synergetic effects between Pd NPs and NBCNHs lead to enhanced catalytic activity for ORR. NBCNHs, having much more pyrrolic $\mathrm{N}$ (73.34\% pyrrolic $\mathrm{N}$ in NBCNHs; $39.28 \%$ pyrrolic $\mathrm{N}$ in NCNHs) that is effective to ORR as well as charged sites $\left(\mathrm{B}^{+}\right)$ caused by charge redistribution, ${ }^{\mathbf{4}, 51}$ on the one hand play a role as a support for Pd NPs, and on the other hand serve as catalytic active sites for ORR. (ii) The larger pore size distribution of PdNBCNHs can generate easier mass transportation of reactants, resulting in better electrocatalytic activity for ORR than other composite materials. (iii) Compared with other catalysts (PdCNHs $\left(I_{\mathrm{D}} / I_{\mathrm{G}}=1.06\right),{ }^{40} \mathrm{Pd}-\mathrm{BCNHs}\left(I_{\mathrm{D}} / I_{\mathrm{G}}=1.17\right)^{40}$ and PdNCNHs $\left.\left(I_{\mathrm{D}} / I_{\mathrm{G}}=1.20\right)^{40}\right)$, the more defective carbon in PdNBCNHs $\left(I_{\mathrm{D}} / I_{\mathrm{G}}=1.26\right)$ can facilitate the adsorption of oxygen molecules and breakage of $\mathrm{O}-\mathrm{O}$ bond, thus improve the ORR activity. ${ }^{52}$ The disordered and defective carbon are more susceptible to the adsorption of oxygen molecule than the wellordered structure of graphite. ${ }^{53} \mathrm{Pd}-\mathrm{XCNHs}$ exhibit different catalytic activities on the onset potential, which indicates to some extent that there is a direct relationship between the electrocatalytic activity and the structural irregularities. Therefore, NBCNHs with the defective and irregular structures are suitable for electrocatalyst carriers, which provides a new strategy for exploring catalyst carriers.

\section{Conclusions}

In summary, we have successfully synthesized Pd NPs with a diameter of 2-4 $\mathrm{nm}$ dispersed uniformly on doped CNHs via one-step reduction method. As-prepared Pd-NBCNHs has a larger pore size distribution, more pyrrolic $\mathrm{N}$ and defective carbon structures than that of Pd-CNHs, Pd-BCNHs and PdNCNHs. Among all the catalysts, Pd-NBCNHs exhibits the highest catalytic activity for ORR and its onset potential approaches to that of commercial $20 \% \mathrm{Pt}-\mathrm{C}$ owing to the synergistic effect between metal palladium and NBCNHs. Because of possessing lots of pyrrolic $\mathrm{N}$, charged $\mathrm{B}^{+}$sites and defect carbon structures, NBCNHs not only act as a carrier for Pd NPs, but also provide the active sites for oxygen adsorption on the surface of the catalyst. In addition, Pd-NBCNHs shows good long-term stability and resistance to methanol for ORR in alkaline media, which enables it to be a candidate for fuel cell.

\section{Conflicts of interest}

There are no conflicts to declare.

\section{Acknowledgements}

We gratefully thank National Science Foundation of China (No. 21471010 and No. 21875002) and the Ministry of Science and Technology of China (No. 2017YFA024901) for generously supporting this work.

\section{Notes and references}

1 Y. Wang, K. S. Chen, J. Mishler, S. C. Cho and X. C. Adroher, Appl. Energy, 2011, 88, 981.

2 M. S. Dresselhaus and I. L. Thomas, Nature, 2001, 414, 332.

3 M. Shao, Q. Chang, J.-P. Dodelet and R. Chenitz, Chem. Rev., 2016, 116, 3594.

4 L. Dai, Y. Xue, L. Qu, H.-J. Choi and J.-B. Baek, Chem. Rev., 2015, 115, 4823.

5 S. Guo, S. Zhang and S. Sun, Angew. Chem., Int. Ed., 2013, 52, 8526.

6 T. Wang, J. Zhuo, Y. Chen, K. Du, P. Papakonstantinou, Z. Zhu, Y. Shao and M. Li, ChemCatChem, 2014, 6, 1877.

7 J. Lai, B. Huang, Y. Tang, F. Lin, P. Zhou, X. Chen, Y. Sun, F. Lv and S. Guo, Chem, 2018, 4, 1153.

8 Z. Chen, D. Higgins, A. Yu, L. Zhang and J. Zhang, Energy Environ. Sci., 2011, 4, 3167.

9 M. Shao, J. Power Sources, 2011, 196, 2433.

10 M. H. Seo, S. M. Choi, H. J. Kim and W. B. Kim, Electrochem. Commun., 2011, 13, 182.

11 O. Savadogo, K. Lee, K. Oishi, S. Mitsushima, N. Kamiya and K.-I. Ota, Electrochem. Commun., 2004, 6, 105.

12 F. I. Pires and H. M. Villullas, Int. J. Hydrogen Energy, 2012, 37, 17052.

13 E. Negro, K. Vezzù, F. Bertasi, P. Schiavuta, L. Toniolo, S. Polizzi and V. D. Noto, ChemElectroChem, 2014, 1, 1359.

14 Md. R. Miah, J. Masud and T. Ohsaka, Electrochim. Acta, 2010, 56, 285.

15 N. N. Kariuki, X. Wang, J. R. Mawdsley, M. S. Ferrandon, S. G. Niyogi, J. T. Vaughey and D. J. Myers, Chem. Mater., 2010, 22, 4144.

16 D. J. You, S.-a Jin, K. H. Lee, C. Pak, K. H. Choi and H. Chang, Catal. Today, 2012, 185, 138.

17 X. Wang, D. Liu, S. Song and H. Zhang, J. Am. Chem. Soc., 2013, 135, 15864.

18 C. Tan, X. Huang and H. Zhang, Mater. Today, 2013, 16, 29.

19 J.-N. Zheng, S.-S. Li, X. Ma, F.-Y. Chen, A.-J. Wang, J.-R. Chen and J.-J. Feng, J. Power Sources, 2014, 262, 270.

20 M. Yun, M. S. Ahmed and S. Jeon, J. Power Sources, 2015, 293, 380.

21 J. E. Choe, M. Shamsuddin and A. S. Jeon, J. Power Sources, 2015, 281, 211.

22 T. J. Davies, M. E. Hyde and R. G. Compton, Angew. Chem., Int. Ed., 2005, 44, 5121.

23 C. E. Banks, A. Crossley, C. Salter, S. J. Wilkins and R. G. Compton, Angew. Chem., Int. Ed., 2006, 45, 2533.

24 Y. Zhao, L. Yang, S. Chen, X. Wang, Y. Ma, Q. Wu, Y. Jiang, W. Qian and Z. Hu, J. Am. Chem. Soc., 2013, 135, 1201.

25 S. Wang, E. Iyyamperumal, A. Roy, Y. Xue, D. Yu and L. Dai, Angew. Chem., Int. Ed., 2011, 50, 11756. 
26 C. H. Choi, M. W. Chung, H. C. Kwon, S. H. Parka and S. I. Woo, J. Mater. Chem. A, 2013, 1, 3694.

27 Y. Zheng, Y. Jiao, L. Ge, M. Jaroniec and S. Z. Qiao, Angew. Chem., Int. Ed., 2013, 52, 3110.

28 J.-i. Ozaki, N. Kimura, T. Anahara and A. Oya, Carbon, 2007, 45, 1847.

29 C. H. Choi, S. H. Park and S. I. Woo, J. Mater. Chem., 2012, 22, 12107.

30 D. von Deak, E. J. Biddinger, K. A. Luthman and U. S. Ozkan, Carbon, 2010, 48, 3635.

31 W. Zhang, S. Zhu, R. Luque, S. Han, L. Hu and G. Xu, Chem. Soc. Rev., 2016, 45, 715.

32 Y. Tao, D. Noguchi, C.-M. Yang, H. Kanoh, H. Tanaka, M. Yudasaka, S. Iijima and K. Kaneko, Langmuir, 2007, 23, 9155.

33 S. Zhu and G. Xu, Nanoscale, 2010, 2, 2538.

34 Z. Zhang, S. Han, C. Wang, J. Li and G. Xu, Nanomaterials, 2015, 5, 1732.

35 X. Wu, L. Cui, P. Tang, Z. Hu, D. Ma and Z. Shi, Chem. Commun., 2016, 52, 5391.

36 L. Yang, S. Jiang, Y. Zhao, L. Zhu, S. Chen, X. Wang, Q. Wu, J. Ma, Y. Ma and Z. Hu, Angew. Chem., Int. Ed., 2011, 50, 7132.

37 S. Ni, Z. Li and J. Yang, Nanoscale, 2012, 4, 1184.

38 X. Wu, L. Liu, P. Tang, M. Li and Z. Shi, RSC Adv., 2016, 6, 63730.

39 N. Li, Z. Wang, K. Zhao, Z. Shi, Z. Gu and S. Xu, Carbon, 2010, 48, 1580 .
40 X. Tan, X. Wu, Z. Hu, M. Ding and Z. Shi, RSC Adv., 2017, 7, 29985.

41 Y. Yan, X. Jia and Y. Yang, Catal. Today, 2016, 259, 292.

42 F. Wolfers, C. R. Hebd. Seances Acad. Sci., 1923, 177, 75.

43 C. Poonjarernsilp, N. Sano, T. Charinpanitkul, H. Mori, T. Kikuchi and H. Tamon, Carbon, 2011, 49, 4920.

44 J. Zheng, T. C. Ekstrom, S. K. Gordeev and M. Jacob, J. Mater. Chem., 2000, 10, 1039.

45 D. Y. Kim, C.-M. Yang, H. Noguchi, M. Yamamoto, T. Ohba, H. Kanoh and K. Kaneko, Carbon, 2008, 46, 611.

46 Z.-H. Sheng, H.-L. Gao, W.-J. Bao, F.-B. Wang and X.-H. Xia,J. Mater. Chem., 2012, 22, 390.

47 H. Jin, T. Xiong, Y. Li, X. Xu, M. Li and Y. Wang, Chem. Commun., 2014, 50, 12637.

48 J. Zhu, C. He, Y. Li, S. Kang and P. K. Shen, J. Mater. Chem. A, 2013, 1, 14700.

49 J.-i. Ozaki, T. Anahara, N. Kimura and A. Oya, Carbon, 2006, 44, 3358.

50 S. Basu, Recent Trends in Fuel Cell Science and Technology, New Delhi, 2007.

51 C. H. Choi, M. W. Chung, S. H. Park and S. I. Woo, Phys. Chem. Chem. Phys., 2013, 15, 1802.

52 L. P. Zhang, Q. Xu, J. Niu and Z. Xia, Phys. Chem. Chem. Phys., 2015, 17, 16733.

53 A. Eftekhari and H. Garcia, Materials Today Chemistry, 2017, 4, 1 . 